\title{
Genetic screening with the DNA chip: a new Pandora's box?
}

\author{
Wolfram Henn Institute of Human Genetics, Saarland University, Homburg/Saar, Germany
}

\begin{abstract}
The ethically controversial option of genetic population screening used to be restricted to a small number of rather rare diseases by methodological limitations which are now about to be overcome. With the new technology of DNA microarrays ("DNA chip"), emerging from the synthesis of microelectronics and molecular biology, methods are now at hand for the development of mass screening programmes for a wide spectrum of genetic traits. Thus, the DNA chip may be the key technology for a refined preventive medicine as well as a new dimension of eugenics. The forthcoming introduction of the DNA chip technology into medical practice urgently requires an internationally consistent framework of ethical standards and legal limitations if we do not want it to become a new Pandora's box. (Fournal of Medical Ethics 1999;25:200-203)
\end{abstract}

Keywords: DNA microarray; genetic screening; eugenics

The development of molecular techniques for genetic analysis and the deciphering of the human genome have provided tools for the diagnosis of a rapidly growing number of heritable diseases. Genetic diagnosis, however, differs from clinical laboratory diagnosis in two fundamental aspects of ethical relevance: clinical laboratory diagnosis aims at disease-associated parameters that arise only after the onset of the pathologic organic process, whereas inborn genetic anomalies that cause heritable diseases are independent of the somatic course of the disease and thus generally are detectable anytime in the patient's life and even prenatally. This dissociation between genetic disposition and somatic disease allows the diagnosis of late-onset hereditary diseases many years before the onset of symptoms as well as the detection of individual risk factors disposing to multifactorial disease. This predictive aspect of genetic diagnosis opens new perspectives for preventive medicine but also for genetic discrimination. ${ }^{1}$

Moreover, molecular genetic diagnosis allows the detection of heterozygous mutations of recessive disease genes. These genetic alterations are completely compensated by the functioning seoond copy of the respective gene and thus insigni cant for the mutation carrier's own health but mey bear a risk for offspring to be sick. As an example, one out of twenty whites carries a heterozygous mutation in the cystic fibrosis gene which, by itself, causes no health problems. Howevif, children whose parents are both heterozygous for cystic fibrosis have a $25 \%$ risk of being homzygous and, if so, of suffering from serious lung and pancreatic disease. Consequently, the miglecular genetic proof of heterozygosity can determine the decision of a couple not to have childre or to request a prenatal diagnosis in case of ${ }^{\circ}$ a pregnancy. This prospective dimension of gene diagnosis that goes beyond individual health case may support autonomous reproductive decisi making but also bears the danger of extern encroachments on parental autonomy.

\section{Ethical acceptance of genetic screening programmes}

The technological feasibility of detecting heter⿳亠二口犬zygous carriers of recessive diseases leads to the question to what extent heterozygosity tesits should be applied in clinical practice. Three basic strategies can be taken into account:

- Individual diagnosis within affected families, $\stackrel{\circ}{\mathrm{g}} \mathrm{r}$ example, for siblings of a patient who suffes from cystic fibrosis;

- Screening within unaffected families offered $\mathscr{T O}^{\circ}$ pregnant women and their partners, coup sts planning to have children, or premaritally populations with a high heterozygote frequengy for the respective disease ${ }^{2-4}$;

- comprehensive population screening for बी individuals at the age of reproduction. ${ }^{5}$

The ethical evaluation of these strategies show substantial international differences. The searoh for heterozygotes within affected families Is unanimously accepted worldwide with bro consensus on the individuality of the decision 80 undergo the test and emphasis on the right notgo know. ${ }^{6}$ Population screening for heterozygotes, of 
the other hand, is still a matter of controversy..$^{7-8}$ More than one million people have already participated in screening programmes for TaySachs disease in Ashkenazi communities in North America, Australia and Israel $^{3}$; a National Institute of Health consensus statement advocates cystic fibrosis heterozygote testing for the prenatal population and couples currently planning a pregnancy but not for the general population. ${ }^{9}$ In Europe, genetic screening is regarded with more reserve. In particular, geneticists in the Germanspeaking countries still object to the introduction of population screening programmes and even to pilot studies, with historical reference to the abuse of genetics in Nazi Germany. ${ }^{10}$ Anyway, there is broad international consensus on the importance of voluntariness and medical secrecy as well as the rejection of any kind of discrimination resulting from unfavourable test results. ${ }^{11}$ Moreover, there is widespread concern about the extreme amount of educational work required to obtain informed consent from participants in large-scale genetic screening programmes. ${ }^{12}$

Doubt about confidentiality and the danger of "genetic discrimination" are discussed as well in the context of predictive genetic screening. Data on individual genetic risk factors such as disturbances of fat metabolism predisposing to atherosclerosis or resistance to toxic factors at the workplace would be of great interest to insurers and employers. ${ }^{13}$ Genetic tests as a prerequisite for jobs or life insurance are not yet within sight due to ethical concerns ${ }^{14}$ and, most of all, not yet realistic because of the lack of scientific knowledge about the complex interactions of genetic and environmental factors.

It may be said that the application of genetic screening programmes is, at present, mainly limited by a shortage of technological and financial resources. At today's state of genome analysis, only a few hereditary diseases and risk factors are accessible to genetic analysis. Moreover, the cost of mutation analysis using conventional techniques of molecular genetics (for example, DNA sequencing or single strand conformation analysis) is a major obstacle to the introduction of extensive screening programmes. Consequently, the development of faster and cheaper technologies for large-scale gene analysis has been at the centre of interest of the genome business for the last few years.

\section{Technical principle of the DNA chip}

Earlier than expected even by most experts, the "DNA chip" appears to overcome the technical limitations of genetic mass screening through the synthesis of computer and DNA technologies. ${ }^{15} 16$
A silicon chip, as used for microelectronic circuits, is photochemically covered by a microarray of exactly defined short sequences of synthetic DNA; a thumbnail-sized chip can harbour up to 400,000 different such oligonucleotides. These standard sequences can be simultaneously checked for identity with the corresponding sequences of a proband's genome; the evaluation is done automatically with a computerised laser scanner. The whole procedure only takes a few hours. This "massively parallel" approach to genome analysis addresses a huge amount of genetic parameters from one blood or tissue sample in a single step. ${ }^{17}$ Thus it is ideally suited for the rapid and cheap identification of mutations in disease-relevant genes. Of particular interest is the fact that even heterozygous mutations are readily detected, thus making the DNA chip the ideal tool for genetic screening. Any human tissue is suitable as the DNA source, including chorionic villi for prenatal testing.

A variety of DNA chips are already available for genome research and microbiology, but also, still at laboratory scale but mass-producible, for the fully automatic detection of mutations in the hereditary breast/ovary cancer gene BRCA1 or in the cystic fibrosis gene. ${ }^{18} 19$ The price of a DNA chip is now about $£ 50$ but is rapidly declining. The involvement of large companies such as Hewlett-Packard and Glaxo Wellcome leaves little doubt that the technology will soon be put on the market - with or without a concomitant ethical discussion. The developers are optimistic that within a few years they will be able to offer the automatic analysis of any given individual's complete genetic complement by a set of DNA chips. ${ }^{17}$

\section{Key technology for a new eugenics?}

With its enormous power and efficiency, the DNA chip is about to open new ranges of application to genetic diagnosis which had been thought to remain matters of theoretical discussion for a long time to come. As Stephen Fodor, principal inventor of the chip, coins it: "The applications appear to be only limited by imagination". ${ }^{17}$ In terms of fact, the DNA chip allows the testing of many more genetic parameters in a much shorter time and at much lower prices than conventional gene analysis.

It is an unquestionable blessing for clinical medicine: the increased efficiency and cost reduction by already available chips for HIV resistance analysis in AIDS therapy ${ }^{20}$ or differential diagnosis of mitochondrial myopathies ${ }^{21}$ is evident and should not be a matter of ethical dispute.

A more difficult field of work for the chip developers is the analysis of genetic determinants 
involved in the pathogenesis of common multifactorial diseases like atherosclerosis and diabetes, which have been frustrating for researchers because of the complexity of interacting factors. ${ }^{16}$ The expected outcome may serve as an example of the dichotomy of scientific revolutions in general: the, previously impossible, identification of the genetic factors underlying schizophrenia may provide psychiatrists with powerful new drugs, but it also provides employers and insurers with ethically questionable parameters for aptitude tests. The discussion about genetic discrimination ${ }^{22}{ }^{23}$ will surely take on new aspects.

To me, the most problematic point is that the DNA chip is the ideal tool for the widespread establishment of genetic screening programmes. Today's supply of heterozygosity screening for young couples is restricted to cystic fibrosis and a few rare diseases that are confined to specific populations. The chip, however, will broaden the spectrum of analysable parental traits practically ad libitum. Moreover, prenatal testing for a battery of predictive parameters such as cancer dispositions or neurodegenerative diseases from a chorionic villus sample will be no problem anymore.

Consequently, the idea of prenatal screening of fetuses has already come to the attention of DNA chip developers. ${ }^{15} \mathrm{~A}$ chip design with probes for interesting traits, be they pathological or, conversely, desired, has got what it takes to become a million-seller. The combination of DNA chip screening with preimplantation diagnosis might be the logical next step towards high-tech eugenics.

The subjective choice of genetic traits that are considered as prenatal selection criteria may blur the distinction between preventive medicine and striving for the "perfectly designed" child. After cost-effectiveness analyses have proven that genetic screening can produce considerable savings even for rather rare diseases which require expensive therapies for affected patients, ${ }^{24}$ there is little doubt that health insurers will support extensive screening programmes. The widening of the diagnostic spectrum may also reinforce the already widespread public opinion that the birth of handicapped children should be prevented. ${ }^{25}$ Ultimately, the exclusion of prenatally testable conditions from health insurance cover might serve as a sanction instrument for a new kind of economically motivated negative eugenics that may well become popular in an era of declining prosperity.

\section{Conclusion}

The emerging, powerful DNA chip technology, with its possible impact on medicine and society, urgently requires an interdisciplinary discussion about its benefits and ethical problems, particu- larly with respect to its application for genet screening. Whatever the results may be, the cornerstones of the discourse are evident:

The introduction of the DNA chip is unavoidab The scientific and commercial driving forcess behind it are very strong. Taking into account the undisputable benefits of the technology f $\frac{3}{8}$ research on causal therapies for previously incue able diseases, it is not even desirable to try to stø̊ the development. Anyway, it is a general lesse from history that powerful new technologies cain at best be regulated but never prohibited.

The discussion must aim at an international ethict consensus. Unequal ethical standards between dipferent countries lead to medical tourism and clas medicine, as we had to learn from orgdi transplantations. Someone who wants to circun vent restrictive national laws on embryo transfor today must travel and pay a lot; someone who, in the future, wanted to undergo a genetic test prohibited at home would have to pay a lot as w! but would only have to send a blood sample tolaboratory anywhere in the world.

The discussion must soon begin. The technical development of the DNA chip is already aovanced; the first systems are now being introduce्d into medical practice. The cloned sheep Do $\bar{y}$ only recently demonstrated that a surprising foit accompli does not at all improve the quality of the ethical discourse.

\section{Acknowledgement}

I wish to thank Professor Klaus D Zang for frui ful discussions and continuous support.

Wolfram Henn, MD, is Consultant Clinical Geneticist and Lecturer in Human Genetics at the Institute of Human Genetics, Saarland University, Homburis/ Saar, Germany.

\section{References}

1 Benjamin CM, Adam S, Wiggins S, Theilmann JL, Copley Bloch $M$ et al. Proceed with care: direct predictive testing for Huntington disease. American fournal of Human Genetirs 1994;55:606-17.

2 Doherty RA, Palomaki GE, Kloza EM, Erickson JL, Haddow JE. Couple-based prenatal screening for cystic fibrosis तुं primary care settings. Prenatal Diagnosis 1996;16:397-404. O

3 Kaback M, Lim Steele J, Dabholkar D, Brown D, Levy $: \vec{N}$, Zeiger K. Tay-Sachs disease - carrier screening, prenatal diagnosis and the molecular era. An international perspective, $19 \overline{\mathbf{D}} 0$ to 1993. Fournal of the American Medical Association 1993;2 (ब): 2307-15.

4 Altay C, Yilgör E, Beksac S, Gürgey A. Premarital screening (ึ)r hemoglobinopathies: a pilot study in Turkey. Human Herediny 1996;46:112-14.

5 Burnett L, Proos AL, Chesher D, Howell VM, Longo L, Tedeschi $\mathrm{V}$ et al. The Tay-Sachs disease prevention programmegn Australia: Sydney pilot study. Medical fournal of Australia 1996; 163:298-300 
6 International Huntington Association, World Federation of Neurology. Guidelines for the molecular genetic predictive test in Huntington's disease. Fournal of Medical Genetics 1994; 31:555-9.

7 Hoedemakers R, ten Have H, Chadwick R. Genetic screening: a comparative analysis of three recent reports. Fournal of Medical Ethics 1997;23:135-41.

8 Henn W. Predictive diagnosis and genetic screening: manipulation of fate? Perspectives in Biology and Medicine 1998;42:2829.

9 NIH Consensus Statement, 1997. Genetic Testing for Cystic Fibrosis. NIH Consens Statement Online 15 (4): in press.

10 Wolff G, Neitzel H, Nippert I, Schwinger E, Vogel W, Zerres K et al. Positionspapier der Gesellschaft für Humangenetik. Medizinische Genetik 1996;1:125-31.

11 American Society of Human Genetics. Statement of the ASHG on cystic fibrosis carrier screening. American fournal of Human Genetics 1992:51:1443-4.

12 Welkenhuysen M, Evers-Kiebooms G, Decruynaere $M$, van den Berghe H, Bande-Knops J, van Gerven V. Adolescents' attitude towards carrier testing for cystic fibrosis and its relative stability over time. European fournal of Human Genetics 1996;4: $52-62$.

13 Birmingham K. Insurers admit genetic discrimination. Nature Medicine 1997;3:710.

14 Rothenberg K, Fuller B, Rothstein M, Duster T, Kahn MJE, Cunningham $\mathrm{R}$ et al. Genetic information and the workplace: legislative approaches and policy challenges. Science 1997; 275: 1755-7.

15 Anonymous. To affinity ... and beyond! [editorial]. Nature Genetics 1996;14:367-70.
16 Gibbs WW. New chip off the old block. Can DNA microprobes do for genetics what microprocessors did for computing? Scientific American 1996;275:42.

17 Fodor SPA. Massively parallel genomics. Science 1997;277: 393-5.

18 Hacia JG, Brody LC, Chee MS, Fodor SPA, Collins FS. Detection of heterozygous mutations in BRCA1 using high density oligonucleotide arrays and two-colour fluorescence analysis. Nature Genetics 1996;14:441-7.

19 Cronin MT, Fucini RV, Kim SM, Masino RS, Wespi RM, Miyada CG. Cystic fibrosis mutation detection by hybridization to light-generated DNA probe arrays. Human Mutation 1996;7:244-55.

20 Kozal MJ, Shah N, Chen N, Yang R, Fucini R, Merigan TC et al. Extensive polymorphisms observed in HIV-1 clade B protease gene using high-density oligonucleotide arrays. Nature Medicine 1996;2:753-9.

21 Chee M, Yang R, Hubbell E, Berno A, Huang XC, Stern D et al. Accessing genetic information with high-density DNA arrays. Science 1996;274:610-14.

22 Hudson K, Rothenberg K, Andrews L, Kahn M, Collins F. Genetic discrimination and health insurance: an urgent need for reform. Science 1995;270:393-5.

23 Moskowitz DW. Genetic screening and diagnosis of disease. Molecular Medicine Today 1996;2:275.

24 van der Riet AAPM, van Hout BA, Rutten FFH. Cost effectiveness of DNA diagnosis for four monogenic diseases. fournal of Medical Genetics 1997;43:741-5.

25 Council on Ethical and Judicial Affairs, American Medical Association. Multiplex genetic testing. Hastings CenterReport 1998;28:15-21. 